\title{
Legionellosis in Japan: A Self-inflicted Wound?
}

\author{
Tetsuya Tanimoto ${ }^{1}$, Kenzo Takahashi ${ }^{2}$ and Andy Crump ${ }^{3}$
}

\begin{abstract}
:
Legionellosis is a serious bacterial infection characterized by atypical pneumonia primarily due to infection with Legionella pneumophila, and bathing can be a potential cause of this infection. Legionellosis was first identified in 1977, and it is caused by Gram-negative bacteria belonging to the genus Legionella. Legionellosis remains an important public health threat, particularly in Japan, where the population is rapidly aging, thereby becoming more at risk of developing severe disease and accompanying life-threatening pneumonia. The bacteria are most commonly transmitted via the inhalation of contaminated aerosols produced and broadcast via water sprays, jets or mists. Infection can also occur via the aspiration of contaminated water or ice, or through inhalation of contaminated dust. Because the signs and symptoms of Legionnaires' disease (LD), as well as radiographic imaging are similar to pneumonia caused by other pathogens, a specific diagnostic test is required, such as a urine antigen detection test. Six clinical and laboratory parameters, a high body temperature, a non-productive cough, low serum sodium and platelet counts, and high lactate dehydrogenase $(\mathrm{LDH})$ and c-reactive protein concentrations can be used to reliably predict the likelihood of LD. The first choices for chemotherapy are fluoroquinolone and macrolide antibiotic drugs. The main goals of LD prevention measures are 1) the prevention of microbial growth and biofilm formation, 2) the removal of all biofilm formed on equipment and in facilities, 3) minimizing aerosol splash and spread, and 4) minimizing bacterial contamination from external sources. It is apparent that, in Japan, where hot spring (onsen) bathing is common among aged people, strict regulations need to be in place - and enforced - to ensure that all Japanese onsens and spas provide a safe environment and undertake regular, effective infection control practices.
\end{abstract}

Key words: legionellosis, Japan, aging society, hot springs, spas

(Intern Med 60: 173-180, 2021)

(DOI: 10.2169/internalmedicine.4852-20)

\section{Introduction}

Immersing your body in water can be both pleasant and therapeutic, and various techniques have been used over the centuries for a diverse range of physiological effects, such as healing injuries, reducing swelling, cooling burns, easing the birth process, and for psychologically calming effects. In Japan, the nation's fabled hot springs (onsen) are a major source of legionellosis, along with the nation's many public baths. Legionnaires' disease (LD) is a serious bacterial infection characterized by atypical pneumonia. It is caused by Legionella bacteria, ubiquitous in nature where they thrive in water and moist environments. When aerosolized, as occurs in water-related cooling systems, water spraying systems, spa pools, and the like, the inhalation of particles con- taminated by the opportunistic waterborne Legionella bacteria can cause potentially fatal disease $(1,2)$.

Bathing has long been recognized as a potential source of infectious disease. But legionellosis is a collection of infections that only emerged in the second half of the 20th century. Legionellosis was first identified in 1977, following the 1976 annual convention of the American Legion in the United States, when 221 participants developed pneumonia, of whom 34 died. The Legionella bacterium has since been shown to exist virtually worldwide and the number of cases of legionellosis have been rising steadily since the turn of the century. Once the causative pathogen was found, surveillance and monitoring systems were developed and implemented in several countries to help avoid further outbreaks (3). Nevertheless, hot tubs, whirlpools, spa pools and natural hot springs remain an important source of infection

${ }^{1}$ Medical Governance Research Institute, Japan, ${ }^{2}$ Teikyo University Graduate School of Public Health, Japan and ${ }^{3}$ Kitasato University, Japan Received: March 16, 2020; Accepted: June 3, 2020; Advance Publication by J-STAGE: July 28, 2020

Correspondence to Dr. Andy Crump, acys@me.com 
of Legionella bacteria. Many bathers remain ignorant of the fact that their desire to relax and soak in a hot bath may be endangering their health and even risking their lives. Today, most cases of legionellosis occur from man-made water sources and uses, although the chances of natural water in rivers and lakes being a source of legionellosis appear to be negligible (4). However, in Japan, an ever-increasing number of cases each year, resulting in $>50$ deaths annually, indicate that the systems in the country are clearly failing to adequately protect the health of its citizens with respect to legionellosis.

\section{Causative Agent}

The majority of reported outbreaks have been due to infection with Legionella pneumophila, in particular serogroup 1. Other serogroups and species have also been associated with human disease, including L. micdadei (now classified as Tatlockia micdadei), L. dumoffii, and L. longbeachae (5). The genus Legionella actually comprises $>50$ species, of which around 30 can infect humans, primarily producing lower respiratory tract infections (6). Legionella bacteria are aerobic, Gram-negative, non-spore forming gamma proteobacteria with restrictive growth requirements. They are ubiquitous in natural freshwater environments including rivers, lakes, streams, fountains, damp soil and hot springs, where they survive in association with complex biofilm communities and can replicate inside various protozoan hosts. Legionella spp. survive in aquatic systems having a temperature range of $25-37^{\circ} \mathrm{C}$ but can also withstand temperatures of $>50^{\circ} \mathrm{C}$ for several hours and are capable of propagating at low temperatures of $<20^{\circ} \mathrm{C}(7-9)$. Although the concentration of legionellae necessary to cause an infection or outbreak is unknown (10) the quantities of bacteria in natural environments are deemed to be insufficient to lead to infection.

Legionella bacteria are also commonly found in humanmade aquatic environments, such as the water systems of hospitals, hotels, private houses $(11,12)$, cooling towers $(13)$, dental units $(14,15)$, and recreational $(16,17)$ or therapeutic $(18,19)$ aquatic facilities. In these environments they can amplify markedly, enough to lead to infection, with ideal water temperatures, water stagnation, the presence of scale, sediment and biofilm in pipes and fittings all enhancing bacterial production. Temperatures $>60^{\circ} \mathrm{C}$ kill the bacteria but they thrive in water systems maintaining temperatures of $20^{\circ}-50^{\circ} \mathrm{C}$ (optimally $25-42^{\circ} \mathrm{C}$ ). In hot tubs for humans, the water temperature is generally in the optimal range for growth. In Japan, the water in hot tubs usually ranges from $40-43^{\circ} \mathrm{C}$, higher than in Europe $\left(30-40^{\circ} \mathrm{C}\right)(20)$. Legionella survive and grow as parasites within free-living protozoa (amoeba), and within biofilms that develop in water systems. They can infect human cells using a similar mechanism to the one they use to infect protozoa where they multiply prolifically. Most people who are exposed do not become infected and Legionella bacteria do not typically spread directly among humans, although cases of human-tohuman transmission have been suggested (21). The risk factors for infection include an older age, a history of smoking, chronic lung disease, and a poor immune function.

\section{Characteristics of Legionellosis}

Legionellosis is an infectious disease caused by Gramnegative bacteria belonging to the genus Legionella, human disease arising primarily due to infection with L. pneumophila. There are two forms of this disease, the severity of legionellosis varying from a mild febrile illness (Pontiac fever) to a potentially fatal form of pneumonia (Legionnaires' disease). The disease can affect anyone, but principally those who are susceptible due to age, illness, immunosuppression or other risk factors, such as smoking, tend to be the worst affected. In general, advanced age, being male, and similarly having chronic medical disorders, such as end-stage renal disease, cancer, and diabetes are recognised as risk factors for legionellosis (22).

Legionellosis is a respiratory tract infection, the bacteria multiplying within alveolar macrophages. Infection is comparatively harmless for healthy individuals but it can lead to the atypical pneumonia that can be life-threatening. As the symptoms of Legionella pneumonia are not unique, it is hard to differentiate it from other pneumonias based on the symptoms alone. The non-pneumonic Pontiac disease is an acute, self-limiting influenza-like illness usually lasting 2-5 days. The potentially fatal pneumonic LD has an incubation period of 2-10 days. Initially, the main symptoms are fever, headache, malaise, loss of appetite and lethargy. Occasionally, patients may develop muscle pain, diarrhea and mental confusion. There is also usually an initial mild coughing up of blood-flecked phlegm (haemoptysis), which occurs in about one-third of all patients. Commonly observed symptoms in the USA are reported to be fever ( $92 \%$ of patients), pneumonia (90\%), cough (48\%), dyspnea (44\%), disturbed consciousness (17\%), diarrhea $(9.8 \%)$, abdominal pain (2.5\%) and multiple organ failure (8.5\%) (23). Untreated LD usually worsens during the first week. Death occurs through progressive pneumonia with respiratory failure and/or shock and multiple-organ failure. The death rate from LD depends on several factors, including the time after infection until treatment, the severity of the disease, the appropriateness of initial antimicrobial treatment, the setting where the infection was acquired, and host factors of the patient concerned.

The disease is much more severe in patients with immune systems which are either weakened or undeveloped, such as the very young and the elderly, or in individuals receiving treatment with anti-tumor necrosis factor alpha therapy, transplant patients or those with a hematological malignancy.

LD frequently presents with severe pneumonia, which almost always requires hospitalization and can be fatal. The death rate may reach $40-80 \%$ in untreated immunosuppressed patients and individuals who do not get proper treat- 
ment in a timely fashion, but it can be reduced to $5-30 \%$ by commencing treatment early and using appropriate management, depending on the severity of the clinical signs and symptoms. Overall the death rate is usually within the range of $5-10 \%$. The risk of developing legionellosis appears to increase exponentially with age and worldwide, of all reported cases, $75-80 \%$ are in individuals over 50 years of age and $60-70 \%$ are male $(24,25)$. Legionella bacteria are responsible for $2-15 \%$ of patients hospitalized with communityacquired pneumonia (CAP), the disease usually exhibiting a summer or autumn peak in incidence (26). LD is the second-most-common cause of pneumonia (behind only pneumococcal pneumonia) for patients with CAP admitted to intensive care units (27).

\section{Infection Route}

Among the various Legionella species, L. pneumophila serogroup 1 accounts for most of the human infections (28). L. pneumophila, together with other similar species, commonly exist in water in lakes, rivers, creeks, hot springs, spa pools, cooling towers, shower heads, taps, hot water supply systems, evaporative coolers, nebulizers, humidifiers, fountains, garden hoses, solar water-heaters, windshield washers and leaf molds. Other infectious Legionella species can also be found in potting mixes used in gardening. The bacteria are most commonly transmitted via the inhalation of contaminated aerosols produced and broadcast via water sprays, jets or mists. Infection can also occur via the aspiration of contaminated water or ice, particularly in susceptible hospital patients, by exposure of babies during water births, or through inhalation of contaminated dust. There is no direct human-to-human transmission.

The disease is frequently categorized as being community-, travel- or hospital-acquired, depending on where the exposure to infection occurred. It has been especially associated with hotels, cruise ships, hospitals and any facility with complex water-based cooling systems. Respiratory-care devices, such as humidifiers and nebulizers may be inadvertently used with Legionella-contaminated tap water, hence it is necessary to use sterile water wherever possible. Infection sources include biofilm growing on porous natural stones in a bath, which can be full of $L e$ gionella. Indeed, a Japanese legionellosis patient was infected while cleaning bathtubs using a high-pressure water hose (29) and another was infected while handling homemade leaf mold (30). Inside Japanese dwellings, aquatic environments and water-rich locations can be highly contaminated with Legionella, including aquariums and washing machines, and thus may pose a significant risk of Legionella infection, especially among people in high-risk groups (31). However, in Japan, the major sources of infection remain hot springs and public baths (32). Bacterial concentrations found in such sources can range from 520,000 to less than 10 colony forming unit (CFU)/100 mL (20).

\section{Incidence}

The global incidence of LD remains unknown; it is underreported in many countries mainly due to lack of awareness, together with a scarcity of diagnostics and active LD surveillance systems. It is estimated that $\mathrm{LD}$ accounts for $2-9 \%$ of cases of CAP worldwide and around $40 \%$ of cases require hospital intensive care (33). In the USA, the 8,000 hospitalizations due to LD during 1997-2006 cost an estimated $\$ 340$ million (34). The number of LD cases has been steadily rising for two decades. In Europe, the incidence increased continuously during 2013-2017, from 1.2 to 1.8 per 100,000 population in 2017 , the highest figure ever observed. Of the cases with a recorded outcome, $8 \%$ proved fatal. In 2017, 30 European nations reported a total of 9,238 cases, a 30\% increase compared with 2016. The main characteristics of the cases reported in 2017 were similar to those observed in previous years, most being sporadic and community-acquired, with the disease mostly affecting males aged 65 years and above (35). In Japan, legionellosis is a Category IV notifiable infectious disease, meaning that doctors making a diagnosis are legally obliged to notify every case to the government. A significant under-reporting problem occurs due to the disease being a relatively rare form of pneumonia, which many clinicians may not have encountered before, and thus may misdiagnose. Even in countries with effective health services and readily available diagnostic testing, about $90 \%$ of cases of Legionnaires' disease may be missed.

In Japan over the last two decades, cases have continued to increase notably, the increasing number of cases culminating in an annual death toll of well over 50 per year (Figure). The steady increase of cases since 2002 is probably partially as a consequence of Japan's national health insurance scheme starting to cover the cost of antigen-detection in urine by enzyme immunoassay from 2003 and by immunochromatographic assay from 2004, plus the Guidelines for the Management of Community-Acquired Pneumonia in Adults were issued by the Japanese Respiratory Society in 2005, which indicated that moderate/severe/ultra-severe pneumonia cases should undergo a Legionella urinary antigen assay. Elsewhere in the world, LD has also been increasing. In the United States the number of reported cases rose $350 \%$ between 2000-2016. LD has been reported worldwide, with major outbreaks associated with cooling towers in Spain (449 confirmed cases, 2001) and Portugal (377 cases, 2014). In 2015, a cooling tower in the Bronx, New York, was associated with 138 cases of LD. Travelassociated outbreaks are also commonly being reported, with 51 confirmed cases of LD associated with travel to Dubai in 2016-2017 (36).

It is believed that the seasonality associated with this disease is related to humidity and the annual peak for legionellosis cases in Japan occurs in July. In 2019, the highest number of cases were reported in Tokyo (187), followed by 


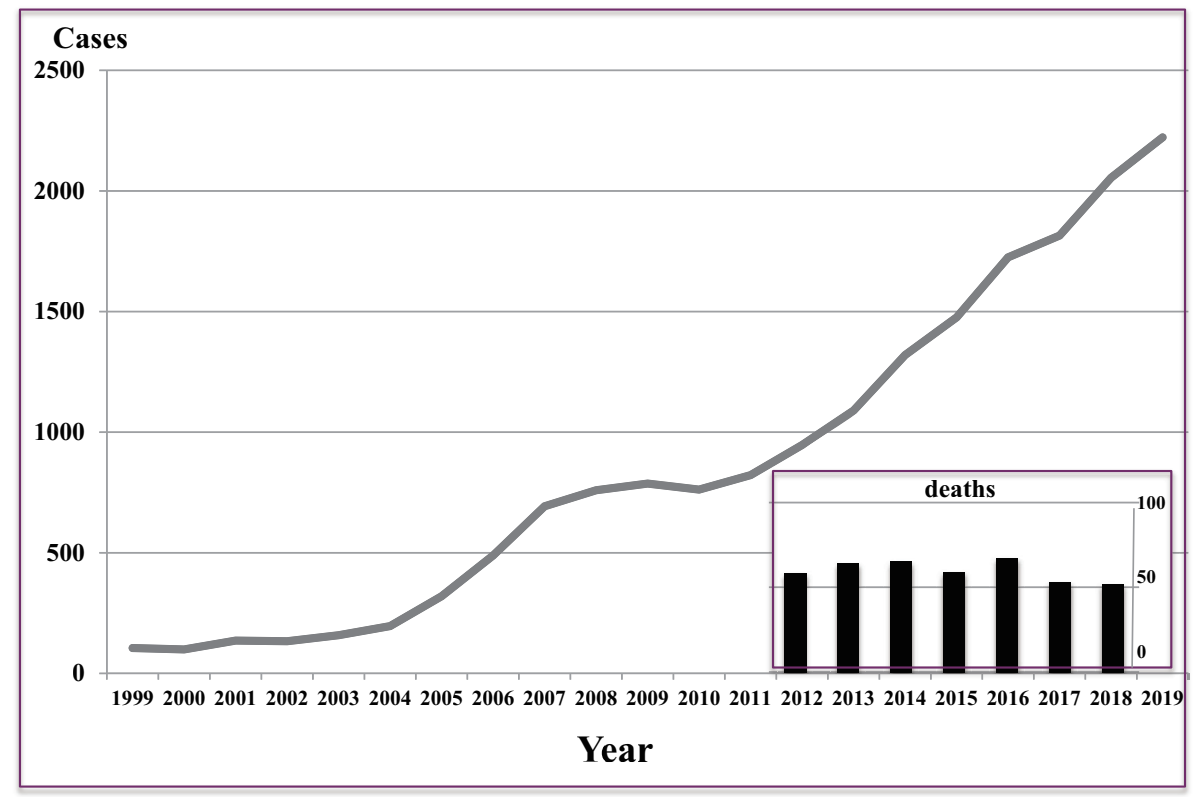

Figure. Legionnellosis in Japan (1999-2019) (3-point moving average) \& deaths from the disease (2012-2018). Data source: National Institute for Infectious Diseases.

Aichi (159), Kanagawa (152) and Osaka (133). In line with the disease impacting the elderly, the average age of patients in Japan is 67 years (65.7 years in males and 72.5 years in females), with a range of $0-103$ years. Only $1 \%$ of cases occur among people $<30$ years of age. Males account for $81 \%$ of Japanese patients.

\section{Diagnosis}

The signs and symptoms of $\mathrm{LD}$, as well as radiographic imaging, including chest X-ray and computed tomography (CT), are similar to pneumonia caused by other pathogens (37), so a specific diagnostic test is required. The Gold Standard for diagnosis is to culture the causative bacterium, collected from coughed-up sputum or material from a broncho-alveolar lavage, on a special growth medium. The process takes 3-5 days but the medium is usually not immediately available at every hospital. Patients can be diagnosed quickly by a urine antigen detection test (UAT), which takes 15 minutes, and in Europe, Japan and the US, over 95\% of LD cases are detected via a UAT. LD can also be diagnosed by the titration of serum antibody, polymerase chain reaction (PCR) [including loop-mediated isothermal amplification (LAMP) method], and by the indirect fluorescent antibody method or the enzyme-linked antibody test. While antigen detection in urine is the preferred option due to its speed, it can only detect the L. pneumophila serogroup 1, which accounts for $80-90 \%$ of cases. The LAMP assay, which can detect a wide range of Legionella species, only began to be covered under Japan's medical insurance program in October 2011. Due to the specific nutrient requirements of Legionella, it will not grow on commonly used standard laboratory media but requires Buffered-Charcoal Yeast Extract Agar (BCYA), which is often only available in special test- ing laboratories, which can thus result in delays in diagnosis (38). The US Centers for Disease Control and Prevention (CDC) recommends that sputum culture and UATs be carried out concurrently (39). The isolation of Legionella by culture is important to detect non-L. pneumophila serogroup 1 species and is necessary to allow comparison of clinical and environmental isolates during an outbreak investigation. Diagnosis by PCR of respiratory secretions is a more recent, evolving technique, which is increasingly being used as it is accurate and relatively rapid. Because of differences in the mechanism of disease, Legionella spp. cannot be isolated from people who have Pontiac fever.

Early diagnosis is important for helping to save lives. The longer the delay from the first consultation to the definitive diagnosis, the higher the fatality rate, i.e., $2.8 \%$ for $0-3$ day delay, $4.2 \%$ for $4-6$ day delay and $5.3 \%$ for $\geq 7$ day delay (40).

Among laboratory parameters, a low sodium level (hyponatremia) is commonly found in patients with CAP, particularly if caused by L. pneumophila, but the true linkage between the two remains unknown (41-44). It should be noted that, a decade ago, a new diagnostic tool was introduced to help differentiate CAP. Six clinical and laboratory parameters, a high body temperature, a non-productive cough, low serum sodium and platelet counts, and high lactate dehydrogenase (LDH) and c-reactive protein (CRP) concentrations, computed as a diagnostic score, can be used to reliably predict the likelihood of LD in patients who present with CAP (45). Notably, in early 2020, following the Coronavirus disease-2019 (Covid-19) pandemic, a case of Severe Acute Respiratory Syndrome Coronavirus 2 (SARS-CoV-2) and Legionella co-infection was discovered (46), manifesting as pneumonia with gastrointestinal symptoms. This highlights the necessity of making an accurate and rapid differ- 
ential diagnosis of CAP.

\section{Treatment}

There is no vaccine for LD nor any effective prophylaxis. The first choices for chemotherapy are fluoroquinolone and macrolide antibiotic drugs. For adults, the fluoroquinolone Levofloxacin (750-1000 mg/day for 5-10 days) is regarded as the treatment of choice for confirmed legionellosis. The second line options are 3-5 day treatment with azithromycin, erythromycin, moxifloxacin or doxycycline $(47,48)$. Macrolides (azithromycin) can be used in all age groups, especially for pediatric therapy, while tetracyclines (doxycycline) are prescribed for children above the age of 12 and quinolones above the age of 18. Rifampicin may also be used, in combination with a quinolone or macrolide, although its effectiveness remains uncertain, and the Infectious Diseases Society of America does not recommend its use. Tetracyclines and erythromycin led to improved outcomes compared to other antibiotics in the original American Legion outbreak. These antibiotics are effective because they have robust intracellular penetration in Legionella-infected cells. Treatment with inappropriate antibiotics can lead to a sudden worsening of the disease. The use of appropriate antibiotic treatment is essential and should be administered as promptly as possible, even while diagnostic tests are being processed. Water management programs to safeguard water systems and devices at risk for Legionella growth and transmission can lower the potential for infection and outbreaks, and travelers at increased risk for infection, such as the elderly or those with immunocompromising conditions such as cancer or diabetes, should avoid high-risk locations such as hot tubs.

\section{Outbreaks in Japan}

In Japan, circulating bath water at a hot spring resort in Shizuoka Prefecture infected 23 people in 2000, two of whom died. A 2002 outbreak also occurred in Kagoshima, with hot spring water as the suspected source of infection, involving nine confirmed patients and one death. Infection came from circulating bath water in two newly opened spa resorts, and the Legionella bacteria in $100 \mathrm{~mL}$ of bath water were found to be $1.5 \times 10^{6}$ and $1.3 \times 10^{5} \mathrm{CFU}$, respectively (49). These outbreaks resembled two previous outbreaks occurring at spa resorts making use of circulating bath water in Ibaraki Prefecture and the 2000 Shizuoka outbreak (50). A subsequent outbreak in 2002 at a spa resort in Miyazaki Prefecture, where circulating bath water was also the source of infection, involved 295 individuals (34 confirmed cases and 7 deaths) which represents the largest reported outbreak in Japan (49). In 2006, two cases arose from use of a whirlpool spa at a fitness club in Niigata City (51), two cases came from a public bathing facility in Kobe City in 2008, and two cases were identified in a welfare facility for the elderly in Okayama Prefecture the same year.

Other outbreaks during 2008-2012 include two cases at a public bathing facility in Kobe City in 2008 (52); two cases at a welfare facility for the elderly in Okayama Prefecture in 2008 (53); eight cases attributable to a bathing facility in a hotel in Gifu Prefecture in 2009 (54); nine cases from a bathing facility in a sports club in Yokohama City in 2011; three cases attributable to a bathing facility in a hotel in Yamagata Prefecture in 2012; and nine cases identified from a hot spring in Saitama Prefecture in 2012. With respect to non-onsen/bathing situations, between 2003-2008; three cases were reported from cruise-ship spas in 2003 (55), and two cases were found among workers engaged in maintenance of a cooling system at a waste processing plant in Kyoto City in 2003. In addition, after the tsunami associated with the Great East Japan Earthquake, legionellosis was reported among those who were rescued from drowning or engaged in debris processing.

\section{Control Measures}

Prevention of LD depends on control activities to minimize the growth of Legionella and avoid the creation of aerosols. These measures include proper maintenance of devices, especially regular cleaning and disinfection, and application of other physical (temperature) or chemical measures (biocide) to minimize bacterial growth. Key examples are the necessity for regular maintenance, cleaning and disinfection of cooling towers at energy production plants and factories, together with frequent or the continuous addition of biocides and the installation of drift eliminators to reduce the dissemination of aerosols from the towers; maintaining an adequate level of a biocide, such as chlorine, in a spa pool together with a complete drain and thorough clean of the whole system at least weekly; keeping hot and cold water systems clean and either keeping the hot water above $50^{\circ} \mathrm{C}$ (which requires water leaving the heating unit to be at or above $60^{\circ} \mathrm{C}$ ) and the cold water below $25^{\circ} \mathrm{C}$ (and ideally below $20^{\circ} \mathrm{C}$ ) or alternatively treating them with a suitable biocide to limit growth, particularly in hospitals and other health care settings, and aged-care facilities; minimizing stagnant water by flushing unused taps in buildings on a weekly basis (56).

The main goals of LD prevention measures are 1) the prevention of microbial growth and biofilm formation, 2) the removal of all biofilm formed on equipment and in facilities, 3) minimizing aerosol splash and spread, and 4) minimizing bacterial contamination from external sources. Consequently, wherever possible, water should be disinfected and checked by culturing of microbes from the water source. The current hygienic requirements for bath water that may pose a risk of aerosol inhalation is Legionella counts of $<10 \mathrm{CFU} / 100 \mathrm{~mL}$. The walls of bath rooms and inner surfaces of water tanks should be cleaned regularly, with those doing the cleaning or who handle leaf mold ensuring they wear appropriate protective face masks. Hygienic control for the prevention of 
legionellosis should follow established guidelines, such as the Legionella Control Measures (stipulated by the Ministry of Health, Labour and Welfare: MHLW), rules for Building Hygiene (MHLW), Guidelines for prevention of legionellosis (3rd Ed., Building Management Education Center) and guidance included in the Introduction to hygienic maintenance of storage-type hot-water supply equipment (Japan Water Facilities Environmental Hygiene Association).

For the prevention of legionellosis, infection sources should be identified by analyzing data obtained from pulsedfield gel electrophoresis and sequence-based typing using Legionella obtained from both patients and the suspect environment. With such evidence, disinfection and/or removal of Legionella can be effectively accomplished.

Obviously from the incident in which a case was infected from an ultrasonic humidifier (57), it is important to clean the inside of the tank of the humidifier for prevention of legionellosis. Although there are practically no reports of infection by aerosol derived from cooling towers and biological treatment plants in Japan, continual monitoring is necessary.

In the mid-1990s, Legionella bacilli and their host amoeba were detected from about $70 \%$ of water samples of hot bathtubs with circulating systems (58). Unless the necessity for hygienic maintenance of bathing equipment and regular cleansing of other potential sources of infection is widely understood and practiced by everybody, then largescale outbreaks will continue to occur. Special care is also necessary for hygienic maintenance of air conditioners, hot water systems, bathing equipment, and humidifiers at various facilities and hospitals, particularly for vulnerable at-risk groups such as the elderly and newborns.

Certain operating conditions that facilitate the formation of aerosols, such as the high temperature of the water and the presence of hydromassage systems, are risk factors inherent to this kind of recreational water. In hot tubs and similar facilities, it is impractical to maintain a water temperature outside the range considered at risk. Therefore, other management strategies need to be implemented, which may include appropriate design and adequate disinfection residual and proper maintenance and cleaning of equipment as well as adequate ventilation. Features, such as water sprays, should be periodically cleaned and flushed with a level of disinfectant adequate to eliminate Legionella spp. $(59,60)$.

\section{Specific Situations in Japan}

Legionellosis remains an important public health threat, particularly in Japan, where the population is rapidly aging, thereby becoming more at risk of developing severe disease and accompanying life-threatening pneumonia. Forty years after the identification of L. pneumophila as the cause of the original 1976 pneumonia outbreak in a hotel in Philadelphia, non-culture-based diagnostic tests, effective antibiotics, and preventive measures to combat LD are all widely available. Yet, irrespective of the progress, the disease still exhibits a mortality rate of around $10 \%$, there is significant underreporting of infection, and sporadic outbreaks occur on a regular basis.

A variety of complex and interacting factors are contributing to the increase in LD being witnessed around the world. These include better monitoring and surveillance, aging populations, increased travel and changing climate and weather patterns. Climate change, particularly global warming, diversifying rainfall patterns and increased humidity, have been associated with higher LD incidence, probably through an effect on bacterial ecology and reproduction and/ or the increased use of aerosol-producing devices or installations, such as cooling towers and air conditioning units that use water.

So what might account for the steady increase in LD cases in Japan? The reasons are many. One possibility is the aging of the population. Age-related immunosenescence could be a contributing factor, as would the tendency for micro-aspiration which increases with age, both of which would be consistent with the age distribution of legionellosis. The aging Japanese infrastructure, particularly in the homes of the elderly, is also a possible contributing factor. Behind many facades of old buildings, no matter how polished they appear, lies a lot of old plumbing, water storage systems and other locations where Legionella can breed. Increasing rainfall because of climate change may also play a role (26). Another theory is that vehicles driving on wet surfaces may further distribute the aerosolized bacteria. The increase in cases may also reflect that diagnostic tests are being used more extensively. Physicians are now much more aware of the disease and infections and will increasingly include LD in the differential diagnosis of patients with pneumonia. Legionella infection can be suspected in any patients where there is a lung finding with or without extrapulmonary features or who display a sub-optimal response to aminopenicillins.

Sporadic Legionella infections, rather than outbreak cases, still account for most Legionella infections in Japan $(61,62)$. However, outbreaks of LD associated with communal bathing facilities also remain a regularly occurrence (63-68), such facilities remain the main source of infection in Japan, even though most operate with filtered circulation systems installed and use natural geothermal water (69). Residential houses are also a potential source of exposure to Legionella bacteria. While most cases of Legionella infection are associated with onsen and public bath facilities (70), some sporadic cases associated with bathing involve residential infections, with a growing and concerning risk of legionellosis from exposure to Legionella bacteria in a variety of aquatic environments in residential houses $(71,72)$.

In Japan, highly sophisticated electronically controlled household baths allow water to be kept in the bath for a long time at a set temperature. In traditional Japanese society, there is a propensity for all the family to use a single bathtub of water, the father bathing first, followed by the 
children and finally the mother. Recently, a 1-month-old girl developed respiratory failure due to bilateral interstitial pneumonia after being bathed in reheated and reused water. A molecular test for sputum and an environmental culture detected L. pneumophila serotype representing the first report of infantile legionellosis contracted from a bathtub at home in Japan (73).

\section{Conclusions}

Legionellosis remains an important cause of potentially preventable morbidity and mortality and there is no sign of the disease burden decreasing. It is apparent that strict regulations need to be in place - and enforced - to ensure that all Japanese onsens and spas provide a safe environment and undertake regular, effective infection control practices, including completion and submission of required documentation, appropriate training of staff, and that customers be made fully aware of the sanitary status of any facilities that they visit and the potential dangers they may face. It is also necessary to increase collaboration between the various professionals involved (including lawmakers and regulators, public health experts, facility managers, technical staff and equipment manufacturers) to provide a constant supply of updated information to onsen and spa owners/operators to ensure compliance with safety and hygiene regulations.

The authors state that they have no Conflict of Interest (COI).

\section{References}

1. World Health Organization. Legionellosis: Key facts. Feb 16, 2018 [Internet]. [cited 2020 Jun 10]. Available from: https://www.who.in t/en/news-room/fact-sheets/detail/legionellosis.

2. Muder RR, You VL, Woo AH. Mode of transmission of Legionella pneumophila: a critical review. Arch Int Med 146: $1607-$ 1612, 1986.

3. Springston JP, Yocavitch L. Existence and control of Legionella bacteria in building water systems: a review. J Occup Environ Hyg 14: 124-134, 2017.

4. Leoni E, Catalani F, Marini S, et al. Legionellosis associated with recreational waters: a systematic review of cases and outbreaks in swimming pools, spa pools, and similar environments. Int J Environ Res Public Health 15: 1612, 2018.

5. Cunha BA, Cunha CB. Legionnaire's disease and its mimics: a clinical perspective. Infect Dis Clin North Am 31: 95-109, 2017.

6. Muder RR. Other Legionella species. In: Principles and Practice of Infectious Diseases. 7th ed. Mandell G, Bennett JE, Dolin R, Eds. Elsevier, Philadelphia, PA, 2010: 2985-2989.

7. Mercante JW, Winchell JM. Current and emerging Legionella diagnostics for laboratory and outbreak investigations. Clin Microbiol Rev 28: 95-133, 2015.

8. Fields BS, Benson RF, Besser RE. Legionella and Legionnaires' disease: 25 years of investigation. Clin Microbiol Rev 15: 506526, 2002.

9. Chaudhry R, Sreenath K, Agrawal SK, et al. Legionella and Legionnaires' disease: time to explore in India. Indian J Med Microbiol 36: 324-333, 2018

10. Bartram J, Bentham J, Briand E, et al. Approaches to risk management. In: Legionella and the Prevention of Legionellosis. Bartram J, Chartier Y, Lee JV, Eds. WHO Press, Geneva, 2007: 39-56.

11. Borella $\mathrm{P}$, Montagna MT, Stampi S, et al. Legionella contamination in hot water of Italian hotels. Appl Environ Microbiol 71
5805-5813, 2005.

12. Leoni E, De Luca G, Legnani P, et al. Legionella waterline colonization: detection of Legionella species in domestic, hotel and hospital hot water systems. J Appl Microbiol 98: 373-379, 2005.

13. Walser SM, Gerstner DG, Brenner B, et al. Assessing the environmental health relevance of cooling towers - a systematic review of legionellosis outbreaks. Int J Hyg Environ Health 217: 145-154, 2014.

14. Dallolio L, Scuderi A, Rini MS, et al. Effect of different disinfection protocols on microbial and biofilm contamination of dental unit waterlines in community dental practices. Int $\mathrm{J}$ Environ Res Public Health 11: 2064-2076, 2014.

15. Ricci ML, Fontana S, Pinci F, et al. Pneumonia associated with a dental unit waterline. Lancet 379: 684, 2012.

16. Donati M, Cremonini E, Di Francesco A, et al. Prevalence of Simkania negevensis in chlorinated water from spa swimming pools and domestic supplies. J Appl Microbiol 118: 1076-1082, 2015.

17. Leoni E, Legnani P, Bucci Sabattini MA, et al. Prevalence of Legionella spp. in swimming pool environment. Water Res 35: 37493753, 2001.

18. Leoni E, Sacchetti R, Zanetti F, et al. Control of Legionella pneumophila contamination in a system for respiratory hydrotherapy with sulphurous spa water. Inf Control Hosp Epidemiol 27: 716721, 2006.

19. Leoni E, Sanna T, Zanetti F, et al. Controlling Legionella and Pseudomonas aeruginosa re-growth in therapeutic spas: implementation of physical disinfection treatments, including UV/ultrafiltration, in a respiratory hydrotherapy system. J Water Health 13: 996-1005, 2015.

20. Kuroki $\mathrm{T}$, Ishihara $\mathrm{T}$, Ito $\mathrm{K}$, et al. Bathwater-associated cases of Legionellosis in Japan, with a special focus on Legionella concentrations in water. Jpn J Infect Dis 62: 201-205, 2009.

21. Correia AM, GonCalves J, Gomes JP, et al. Probable person-toperson transmission of Legionnaires' disease. N Engl J Med 374: 497-498, 2016.

22. Marston BJ, Lipman HB, Breiman RF. Surveillance for Legionnaires' disease. Risk factors for morbidity and mortality. Arch Intern Med 154: 2417-2422, 194.

23. National Institute of Infectious Diseases, Ministry of Health, Labour and Welfare. Infect Agents Surveill Rep 34: 155-157, 2013.

24. Neil K, Berkelman R. Increasing incidence of legionellosis in the United States, 1990-2005: changing epidemiologic trends. Clin Infect Dis 47: 591-599, 2008.

25. Ng V, Tang P, Jamieson F, et al. Laboratory-based evaluation of legionellosis epidemiology in Ontario, Canada, 1978 to 2006. BMC Infect Dis 9: 68, 2009.

26. Sakamoto R. Legionnaire's disease, weather and climate. Bull World Health Organ 93: 435-436, 2015.

27. Vergis EN, Akbas E, Yu VL. Legionella as a cause of severe pneumonia. Semin Respir Crit Care Med 21: 295-304, 2000.

28. Yu VL, Plouffe JF, Pastoris MC, et al. Distribution of Legionella species and serogroups isolated by culture in patients with sporadic community-acquired legionellosis: an international collaborative survey. J Infect Dis 186: 127-128, 2002.

29. National Institute of Infectious Diseases, Ministry of Health, Labour and Welfare. Infect Agents Surveill Rep 29: 49-50, 2008.

30. National Institute of Infectious Diseases, Ministry of Health, Labour and Welfare. Infect Agents Surveill Rep 26: 221-222, 2005.

31. Kuroki T, Watanabe Y, Teranishi H, et al. Legionella prevalence and risk of legionellosis in Japanese households. Epidemiol Infect 145: 1398-1408, 2017.

32. National nstitute of Infectious Diseases, Ministry of Health, Labour and Welfare. Legionellosis, April 1999-July 2000. Infect Agents Surveill Rep 21: 186-187, 2000.

33. Dooling KL, Toews KA, Hicks LA, et al. Active bacterial core surveillance for Legionellosis - United States, 2011-2013. MMWR Morb Mortal Wkly Rep 64: 1190-1193, 2015.

34. Naumova EN, Liss A, Jagai JS, et al. Hospitalizations due to selected infections caused by opportunistic premise plumbing pathogens (OPPP) and reported drug resistance in the United States older adult population in 1991-2006. J Public Health Policy 37: 500-513, 2016 
35. European Centre for Disease Prevention and Control. Legionnaires' disease. In: ECDC Annual Epidemiological Report for 2017. ECDC, Stockholm, 2019.

36. Cooley LA. Legionellosis (Legionnaire's disease \& Pontiac fever). Centers for Disease Control and Prevention. In CDC Yellow Book 2020; Chapter 4 [Internet]. [cited 2020 Jun 10]. Available from: ht tps://wwwnc.cdc.gov/travel/yellowbook/2020/travel-related-infectio us-diseases/legionellosis-legionnaires-disease-and-pontiac-fever.

37. Mittal S, Singh AP, Gold M, et al. Thoracic imaging features of legionnaire's disease. Infect Dis Clin North Am 31: 43-54, 2017.

38. Fields BS, Benson RF, Besser RE. Legionella and Legionnaires' disease: 25 years of investigation. Clin Microbiol Rev 15: 506526, 2002.

39. Centers for Disease Control and Prevention. Legionella (Legionnaires' disease and Pontiac fever). For clinicians [Internet]. [cited 2020 Jun 10]. Available from: https://www.cdc.gov/legionella/clini cians.html.

40. National Institute of Infectious Diseases, Ministry of Health, Labour and Welfare. Infect Agents Surveill Rep 34: 155-157, 2013.

41. Cunha BA. The clinical diagnosis of Legionnaires' disease: the diagnostic value of combining non-specific laboratory tests. J Infect 13: 395-397, 2008.

42. Carratalà J, Garcia-Vidal C. An update on Legionella. Curr Opin Infect Dis 13: 152-157, 2010.

43. Fiumefreddo R, Zaborsky R, Haeuptle J, et al. Clinical predictors for Legionella in patients presenting with community-acquired pneumonia to the emergency department. BMC Pulm Med 13: 4, 2009.

44. Sopena N, Force L, Pedro-Botet ML, et al. Sporadic and epidemic community legionellosis: two faces of the same illness. Eur Respir J 13: 138-142, 2007.

45. Haubitz S, Hitz F, Graedel L, et al. Ruling out legionella in community-acquired pneumonia. Am J Med 127: 1010.e111010.e19, 2014.

46. Arashiro T, Nakamura $\mathrm{S}$, Asami $\mathrm{T}$, et al. SARS-CoV-2 and Legionella co-infection in a person returning from a Nile cruise. $\mathrm{J}$ Travel Med 27: taaa053, 2020.

47. Mandell LA, Wunderink RG, Anzueto A, et al. Infectious Diseases Society of America; American Thoracic, Society (1 March 2007). "Infectious Diseases Society of America/American Thoracic Society consensus guidelines on the management of communityacquired pneumonia in adults". Clinical Infectious Diseases 44 (Suppl 2): S27-S72, 2007.

48. Kolditz M, Lück C. Legionella and Legionellosis. Dtsch Med Wochenschr 144: 1030-1033, 2019.

49. National Institute of Infectious Diseases, Ministry of Health, Labour and Welfare. Infect Agents Surveill Rep 24: 27-28, 2003.

50. National Institute of Infectious Diseases, Ministry of Health, Labour and Welfare. Infect Agents Surveill Rep 21: 186-187, 2000.

51. National Institute of Infectious Diseases, Ministry of Health, Labour and Welfare. Infect Agents Surveill Rep 28: 144-145, 2007.

52. National Institute of Infectious Diseases, Ministry of Health, Labour and Welfare. Infect Agents Surveill Rep 29: 329-330, 2008.

53. National Institute of Infectious Diseases, Ministry of Health, Labour and Welfare. Infect Agents Surveill Rep 29: 330-331, 2008.

54. National Institute of Infectious Diseases, Ministry of Health, Labour and Welfare. Infect Agents Surveill Rep 31: 207-209, 2010.

55. National Institute ofInfectiousDiseases, Ministry of Health, Labour and Welfare. Infect Agents Surveill Rep 25: 40-42, 2004.

56. Bartram J, Chartier Y, Lee JV, et al.; World Health Organization. Legionella and the prevention of legionellosis. Geneva, World Health Organization, 2007 [Internet]. [cited 2020 Jun 10]. Available from: https://apps.who.int/iris/handle/10665/43233.

57. Zhou L, Cui L, Xiong L, et al. A combined outbreak of Legionnaires' disease and Pontiac fever related to an ultrasonic humidifier contaminated with Legionella pneumophila serogroup 1, Nanjing City, China, 2012. J Public Health Emergency [Internet]. [cited 2020 Jun 10]; 1: 78. Available from: http://jphe.amegroups.c om/article/view/4187.
58. Kuroki T, Yagita K, Yabuuchi E, et al. Isolation of legionella and free-living amoebae at hot spring spas in Kanagawa, Japan. Kansenshogaku Zasshi 72: 1050-1063, 1998 (in Japanese, Abstract in English).

59. ECDC. European Technical Guidelines for the Prevention, Control and Investigation of Infections Caused by Legionella Species. June 2017 [Internet]. [cited 2020 Jun 10]. Available from: https://www.e scmid.org/fileadmin/src/media/PDFs/3Research_Projects/ESGLI/ES GLI_European_Technical_Guidelines_for_the_Prevention_Control_ and_Investigation_of_Infections_Caused_by_Legionella_species_Ju ne_2017.pdf.

60. World Health. Organization. Guidelines for Safe Recreational Water Environments. Volume 2, Swimming Pools and Similar Environments; WHO: Geneva, Switzerland, 2006 [Internet]. [cited 2020 Jun 10]. Available from: http://www.who.int/water_sanitation _health/bathing/srwe2full.pdf.

61. Atlas RM. Legionella: from environmental habitats to disease pathology, detection and control. Environ Microbiol 1: 283-293, 1999.

62. National Institute of Infectious Diseases, Ministry of Health, Labour and Welfare. Legionellosis, January 2008-December 2012. Infect Agents Surveill Rep 34: 155-156, 2013.

63. Nakamura H, Yagyu H, Kishi K, et al. A large outbreak of Legionnaires' disease due to an inadequate circulating and filtration system for bath water: epidemiologic manifestations. Intern Med 42: 806-811, 2003.

64. Kura F, Amemura-Maekawa J, Yagita K, et al. Outbreak of Legionnaires' disease on a cruise ship linked to spa-bath filter stones contaminated with Legionella pneumophila serogroup 5. Epidemiol Infect 134: 385-391, 2006.

65. Kawano K, Okada M, Kura F, et al. Largest outbreak of legionellosis associated with spa baths: comparison of diagnostic tests. Kansenshogaku Zasshi 81: 173-182, 2007 (in Japanese, Abstract in English).

66. National Institute of Infectious Diseases, Tuberculosis and Infectious Diseases Control Division. 2000. Legionellosis, April 1999July 2000. Infect Agents Surveill Rep 21: 186-187, 2000.

67. National Institute of Infectious Diseases, Tuberculosis and Infectious Diseases Control Division, Ministry of Health, Labour and Welfare. Legionellosis, January 2008-December 2012. Infect Agents Surveill Rep 34: 155-157, 2013.

68. Kuroki T, Amemura-Maekawa J, Ohya H, et al. Outbreak of Legionnaire's disease caused by Legionella pneumophila serogroups 1 and 13. Emerg Infect Dis 23: 349-351, 2017.

69. Amemura-Maekawa J, Kura F, Chida K, et al. Legionella pneumophila and other Legionella species isolated from Legionellosis patients in Japan between 2008 and 2016. Appl Environ Microbiol 84: pii: e00721-18, 2018.

70. National Institute of Infectious Diseases and Tuberculosis and Infectious Diseases Control Division Ministry of Health, Labour and Welfare. Legionellosis, April 1999-July 2000. Infect Agents Surveill Rep 21: 186-187, 2000.

71. Nagai T, Sobajima H, Iweasa M, et al. Neonatal sudden death due to Legionella pneumonia associated with water birth in a domestic spa bath. J Clin Microbiol 41: 2227-2229, 2003.

72. Pedro-Botet ML, Stout JE, Yu VL. Legionnaires' disease contracted from patient homes: the coming of the third plague? Eur $\mathrm{J}$ Clin Microbiol Infect Dis 21: 699-705, 2002.

73. Tomari K, Morino S, Horikoshi Y. Case of infantile Legionella pneumonia after bathing in reheated and reused water. Pediatr Infect Dis J 37: 370-372, 2018.

The Internal Medicine is an Open Access journal distributed under the Creative Commons Attribution-NonCommercial-NoDerivatives 4.0 International License. To view the details of this license, please visit (https://creativecommons.org/licenses/ by-nc-nd/4.0/).

(C) 2021 The Japanese Society of Internal Medicine

Intern Med 60: 173-180, 2021 